\title{
A elaboração de material didático em ambientes virtuais de ensino- aprendizagem: o desafio da transposição didática
}

\author{
Cláudia Smaniotto Barin, Depto. Química/UFSM, claudiabarin@ufsm.br \\ Giséli Duarte Bastos, CPD/UFSM, giseli.bastos@ufsm.br \\ Débora Marshall, CTISM/UFSM, deboram@ufsm.br
}

\section{Resumo:}

O foco investigativo deste trabalho consiste na produção de material didático digital por estudantes dos cursos de licenciatura em química, física e geografia, problematizada na disciplina complementar de graduação: Ciências Naturais e Exatas mediada por tecnologias educacionais em rede. Metodologicamente desenvolveu-se pesquisa-ação participativa durante elaboração, implementação, análise e replanejamento das atividades de criação de recursos educacionais em ambientes virtuais de ensinoaprendizagem. Como resultado destaca-se a aquisição da fluência necessária para a transposição didática dos saberes na criação de recursos educacionais e atividades de estudo. Os resultados observados apontam que o sucesso da produção dos recursos educacionais requer o desenvolvimento da autonomia, assim como a fluência não só tecnológica como pedagógica para transpor o saber sábio no saber a ser ensinado.

Palavras-chave: transposição didática, recursos educacionais, fluência pedagógica, fluência tecnológica.

\section{Abstract}

This research focus on the production of technology-supported didactic materials for virtual environments by undergraduate students of Chemistry Education, Physics Education, and Geography Education. The production of educational resources was carried out in classes of the subject named Ciências Naturais e Exatas Mediadas por Tecnologias Educacionais em Rede. Production, implementation, and analysis of these materials as well as the re-planning of material production activities were conducted through a participatory action research approach. Results indicate that these students have been enabled with the pedagogical fluency necessary to execute didactic transposition of knowledge with a view to produce educational resources and task-based activities. The results from this study indicate that successful elaboration of educational resources requires developing intellectual autonomy added to technology proficiency and, more than that, pedagogical fluency with Information and Communications Technology in order to transform scientific knowledge into knowledge to be taught.

Keywords: didactic transposition, educational resources, pedagogic fluency, technology fluency

\section{Introdução}

O advento das tecnologias da informação e da comunicação (TIC) tem alterado de forma significativa os espaços de ensinar e aprender. Nesse sentido, o acesso à informação tem se tornado facilitado, mas apresenta como contrapartida a necessidade de seleção e transformação da informação em conhecimento requerendo de educadores e educandos o aprender a educar e o aprender a aprender. Isso requer um nível de fluência e habilidades nas atitudes de pesquisa e exploração investigativa perante os 
meios de acesso as informações, passando do ensino baseado na transmissão do conhecimento para a construção de saberes, proporcionando ao educando experiências que lhe possibilitem ampliar sua capacidade de resolução de problemas e respostas à curiosidade humana (Papert; Resnick,1995). Ser digitalmente fluente envolve não apenas saber como usar ferramentas tecnológicas, mas também saber como construir coisas significativas com essas ferramentas.

Feres (2008) afirma que à medida que a sociedade constata a necessidade da informação no seu processo de construção de competências, a produção e a disseminação do conhecimento científico centrada em tecnologias adquire importância ímpar. Esse processo altera de forma significativa nossa forma de viver, de pensar, de nos comunicar, de nos relacionar e de nos desenvolver.

Para que as TIC possam transformar o processo de ensino-aprendizagem, é necessário que os recursos e as atividades de estudo sejam planejadas e organizadas de forma a flexibilizar a aprendizagem ao educando, despertando o interesse em aprender e promovendo a internalização de conceitos construídos. Isso, no entanto, não garante que as práticas escolares estejam sendo inovadoras em sua totalidade. Porém, implicam um desafio imediato, que é a melhoria nos índices de fluência tecnológica para que se possa explorar cada vez mais o potencial educacional (interatividade, interação e colaboração) das ferramentas (Barin; Ellensohn; Müller, 2012).

Karsenti, Villeneuve e Raby (2008) afirmam que muitos formadores universitários passaram a fazer uso de apresentações de slides para responder a demanda da integração pedagógica das TIC. No entanto, o subaproveitamento das tecnologias nesta perspectiva expositiva não desenvolve nos futuros professores nenhuma capacidade de utilização inovadora das TIC.

Nesse sentido, a formação de professores para o uso das TIC encontra uma complexa rede de possibilidades e necessidades que vai sendo configurada a partir do imbricamento das tecnologias, dos sujeitos (educandos e educadores); da leitura crítica da sociedade e do papel da escola na formação do cidadão. Assim, o desafio que se apresenta é a formação inicial e continuada de professores capaz de promover para além de conhecimentos específicos de natureza científica e pedagógica, a autonomia, a criatividade, a reflexão crítica, o espírito colaborativo, o empreendedorismo e a fluência tecnológica e pedagógica, visto que não são as tecnologias que tornam as ações inovadoras, mas os planejamentos que as transformam. Dessa forma, o desafio de criar soluções para o uso das tecnologias, aliado à coragem, ao desejo de mudança e à criatividade são, portanto, a impulsão que possibilita a inovação na área educacional.

Nas últimas décadas, a discussão acerca das potencialidades dos ambientes virtuais de ensino-aprendizagem (AVEA) na mediação da aprendizagem presencial, híbrida ou a distância tem se ampliado. Para Flores et al. (2008) apud Lisbôa et al (2009), a utilização dessas Plataformas marca um novo paradigma de aprendizagem, que ultrapassa o ensino tradicional, reorientando-se para o construtivismo social, permitindo a construção coletiva do conhecimento, pelas oportunidades de partilha, comunicação, interação e promoção da autonomia que oferece.

O Moodle é um AVEA que possibilita aos educadores e educandos um conjunto de ferramentas de recursos educacionais (página web, link a arquivos e sites, rótulos) e atividades (individuais ou colaborativas), além dos módulos comunicativos e informativos. Isso possibilita a construção de ideias e conhecimentos em grupos de forma colaborativa criando assim uma cultura de compartilhamento de significados conforme os princípios das teorias construtivistas. A mediação pedagógica no Moodle como apoio ao ensino está de acordo com o que preconizam as diretrizes curriculares nacionais tanto do ensino superior quanto da educação básica. Práticas pedagógicas 
mediadas pelas tecnologias educacionais em rede potencializam o processo de ensinoaprendizagem a medida que o tornam mais dinâmico e interativo recriando novas interfaces entre a teoria e a prática.

Com base nos pressupostos apresentados, o objetivo deste trabalho é sistematizar a criação de disciplinas nas áreas de formação dos estudantes da disciplina de Ciências Naturais e Exatas mediadas por Tecnologias Educacionais em Rede, da Universidade Federal de Santa Maria, no AVEA livre Moodle Social, no intuito de gerar conhecimentos e potencializar a autonomia do aprendizado através da fluência tecnológica necessária para o uso das TIC.

\section{Metodologia}

O trabalho foi desenvolvido na Universidade Federal de Santa Maria, na cidade de Santa Maria, RS, Brasil, na disciplina de Ciências Naturais e Exatas mediadas por Tecnologias Educacionais em Rede, sendo esta uma Disciplina Complementar de Graduação (DCG1139). A metodologia utilizada foi a pesquisa-ação participativa (TRIPP, 2005), num paradigma construtivista de uma pesquisa qualitativa (GIL, 2002), a qual implica uma interação do pesquisador com seus sujeitos de investigação para a análise da realidade encontrada e para a construção de conhecimento (Figura 1).
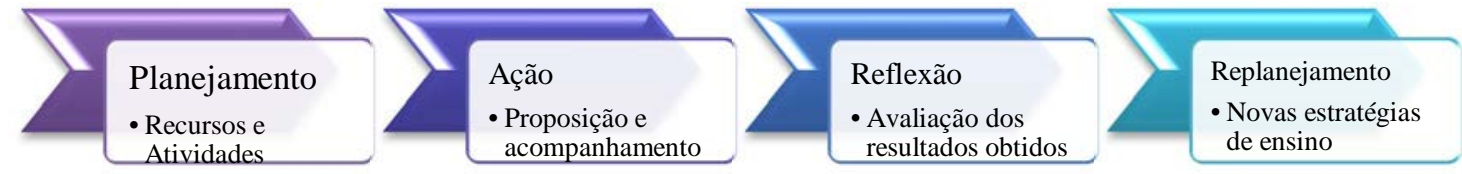

Figura 1 - Estratégia da Pesquisa-ação na DCG 1139.

Os sujeitos de pesquisa foram os estudantes da DCG 1139, composta por estudantes de Licenciatura dos Cursos de Química, Física e Geografia. Como instrumento de pesquisa foram propostas atividades individuais sobre o uso de AVEA e criação de uma disciplina por cada estudante no AVEA Moodle Social. As atividades foram orientadas e monitoradas no decorrer dos módulos 2 e 4 da disciplina DCG 1139. A avaliação dos materiais produzidos foi realizada em seminário aberto com a participação de todos os alunos.

A DCG objetivou desenvolver competências e habilidades para a prática profissional, no âmbito das Ciências Naturais e Exatas, proporcionando fluência tecnológica, em especial a partir dos ambientes virtuais de ensino-aprendizagem. A disciplina ocorre predominantemente no modelo presencial e suas atividades de estudo são planejadas, organizadas e realizadas com apoio do Moodle Institucional da UFSM o qual funciona no endereço http://www.ufsm.br/moodle. A disciplina é composta por quatro unidades (módulos didáticos): 1- Ciência, Tecnologia e Sociedade, 2Tecnologias Educacionais em Rede, 3- Portais Educacionais em Rede e 4 - Ambientes Virtuais de Ensino-Aprendizagem.

No decorrer dos módulos didáticos foram proporcionadas atividades de estudo individuais (envio de arquivo único, diário, texto online, enquete e questionário), bem como colaborativas (glossário, fórum, chat e wiki) com o objetivo de gerar desenvolvimento cognitivo dos estudantes, assim como proporcionar um diálogo a respeito da formação de professores para o uso das tecnologias. Neste trabalho, nos focaremos apenas no Módulo 4: Ambientes Virtuais de Ensino-aprendizagem (Fig. 2).

Após os educandos terem vislumbrado as potencialidades e desafios para o uso dos AVEA foi proposto a eles um desafio mais amplo (desafio final) de criação de uma disciplina no AVEA Moodle Social, composta de, no mínimo, 3 módulos didáticos contendo recursos educacionais e atividades de estudo correlatas. 
Os estudantes foram orientados sobre como realizar o cadastro no ambiente e a solicitação de disciplina. A temática relacionada à disciplina criada ficou a critério de cada educando. A atividade foi orientada durante as aulas presenciais e monitorada por meio das ferramentas de comunicação do AVEA Moodle.

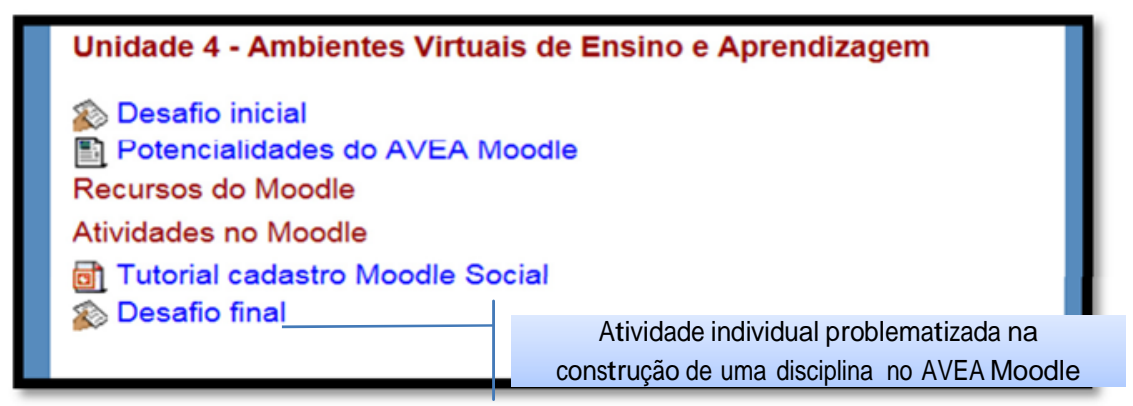

Figura 2 - Módulo 4 da DCG 1139: Ambientes Virtuais de Ensino e Aprendizagem

\section{Resultados e Discussão}

A perspectiva da ação-reflexão-ação adotada na DCG 1139 proporciona o desenvolvimento das habilidades de observação, sistematização, análise e interpretação de dados coletados, e aponta para a necessidade intangível de que o professor no exercício da docência esteja preparado para a imprescindível e constante (re)formulação da práxis. Para tanto, é preciso enriquecer o trabalho pedagógico por meio da atualização e aperfeiçoamento de professores (e futuros professores), problematizando a necessidade de flexibilidade de métodos e critérios, disponibilizando as possibilidades de colaboração, interação e interatividade que as TIC propiciam, através das diversas linguagens (verbal, visual, e digital) para oportunizar o desenvolvimento de metodologias inovadoras.

A primeira etapa da construção da disciplina iniciou com o cadastro do estudante no ambiente virtual de ensino-aprendizagem (AVEA - Moodle Social) e por seguinte solicitação de uma disciplina, para edição. Nesta etapa, os estudantes deveriam preencher o formulário (Figura 3) explicitando o nome da disciplina requerida, suas implicações e fundamentando as razões para solicitação.

Frente ao desafio proposto os estudantes demonstraram, em um primeiro momento, certa resistência ao desenvolvimento da atividade, por compreenderem que a mesma requeria além da fluência tecnológica para a elaboração de recursos e atividades no Moodle, a fluência pedagógica para a transposição didática de saberes. Essa dificuldade em relação à autoria e à autonomia do processo de ensino-aprendizagem pode estar relacionada ao fato da formação dos estudantes ser pautada num modelo tradicional de ensino que não prima pelo desenvolvimento destas competências, que passam a ser exigidas na incorporação da mediação tecnológica.

Segundo Chevallard (1991), os conteúdos de saber instituído como aqueles a ensinar são na verdade criações didáticas, movidas pelas necessidades do ensino. Esse trabalho de transformação do saber sábio ao saber a ser ensinado é o que se denomina transposição didática, assim o saber sábio passa por profundas transformações desde sua produção no meio acadêmico, até chegar à escola, por um processo de textualização. Assim, para se transpor os saberes é preciso considerar a necessidade de adaptações, de tal forma que se responda as perguntas que surgem: o que ensinar? Como ensinar?, Quando ensinar? E a quem ensinar?

No intuito de fornecer subsídios aos estudantes para que respondessem a essas perguntas, eles foram orientados sobre como deveriam proceder para o desenvolvimento da atividade. Para tanto, foi disponibilizado um roteiro contendo o passo a passo da 
criação da disciplina no Moodle Social: i) Estrutura de um curso no Moodle (apresentação da disciplina, nome do professor e tutor/monitor, plano de ensino da disciplina a ser criada no AVEA); ii) Linguagem digital (que deve ser clara e preferencialmente em tom conversacional/dialógico); iii) Recursos (material didáticoinstrucional a ser disponibilizado aos estudantes, sendo preferencialmente àqueles que propiciam maior interação/interatividade, permitindo uma leitura diferenciada); iv) Atividades (atividades que permeiam a disciplina, sendo que estas devem estar sempre relacionadas aos recursos educacionais disponibilizados). O plano de ensino da disciplina deveria conter a ementa, o objetivo, o conteúdo programático, a forma de avaliação e a bibliografia. Esta orientação foi imprescindível para que os mesmos conseguissem organizar a disciplina em seus módulos didáticos, selecionar os conteúdos e prever como trabalhá-los no decorrer da disciplina (transposição didática).

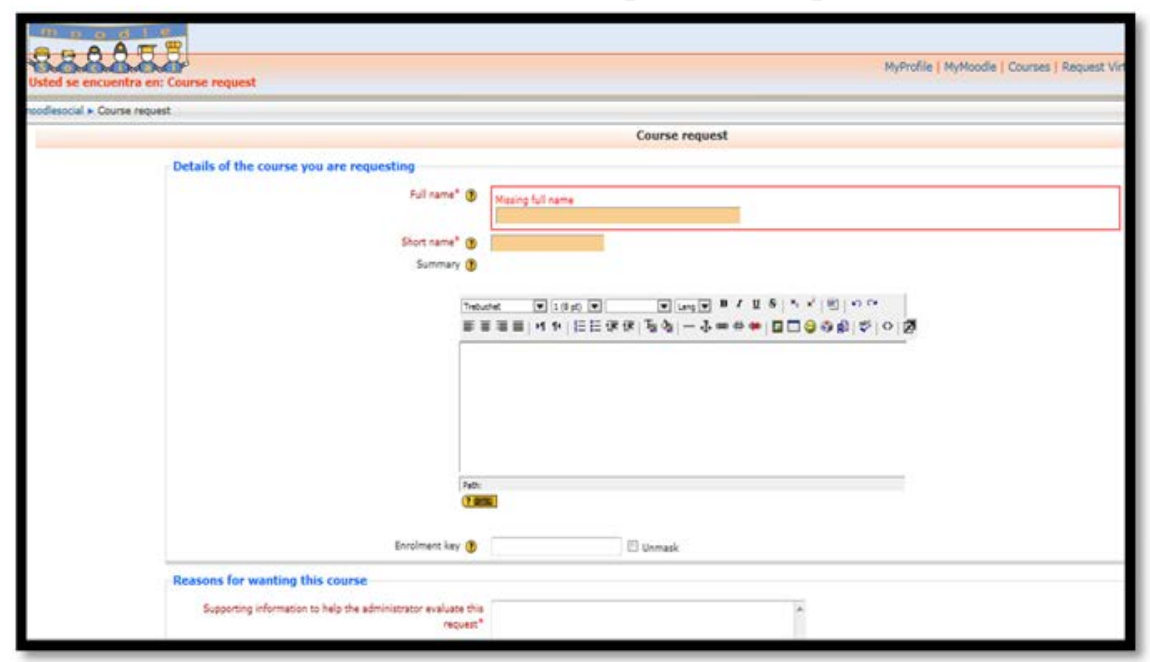

Figura 3 - Página de requisição da disciplina no AVEA Moodle Social.

Debevc, Venuti, Peljhan (2003) afirmam que o material didático requer uma linguagem clara, com conteúdos divididos em unidades ou módulos, com sequência de conteúdos e, deve considerar a qualidade da aprendizagem individual dos estudantes. Assim, a escolha do recurso disponível no AVEA que seja mais adequado a cada conteúdo requer critérios de qualidade, seja no aspecto ético, estético ou de conteúdo. Se o educador compreende as necessidades de seus educandos e o estilo como esses percebem o material, então o professor estará criando um material que pode facilitar o processo de ensino e aprendizagem (flexibilização cognitiva) (Almeida; Silva, 2004).

A etapa seguinte envolveu a criação de recursos e atividades no Moodle Social e no decorrer da aula presencial os alunos exploraram as possibilidades disponibilizadas no AVEA. Explorar as potencialidades dos recursos das TIC em processos de ensinoaprendizagem em rede implica em associar o par recurso-atividade, ou seja, para cada recurso disponibilizado no Ambiente, deve-se disponibilizar uma atividade correspondente. O box de "recursos" no Moodle apresenta as possibilidades de disponibilização de materiais didáticos que variam desde o texto simples a textos diagramados ou mesmo produção de uma página web com links internos e externos, imagens, sons, animações e simulações. O box "atividades" disponibiliza ferramentas para programação de atividades individuais ou colaborativas como por exemplo: tarefas de envio de arquivos, atividade offline e texto online, fórum, chat, wiki, questionário, enquete, glossário, etc. Desta forma, é possível organizar os módulos didáticos no AVEA fazendo as relações entre os objetivos e as finalidades do conteúdo a ser ensinado com as ações e as operações que espera-se que o estudante desenvolva ao realizar as atividades de estudo propostas na disciplina. 
Assim, os educandos foram orientados a selecionar recursos educacionais de caráter hipermidiáticos considerando que estes proporcionam uma leitura diferenciada do conteúdo e potencializam a interatividade e a interação. Mallmann et. al (2012) destacam a importância de transpor os saberes lançando mão das potencialidades hipermidiáticas, para propiciar ações indutoras da interatividade, da interação e da autonomia. A produção de material didático hipermídia, segundo Nobre (2009), é mais complexa do que o material impresso, pois envolve além das etapas de planejamento, construção, mediação e avaliação, as inúmeras possibilidades de combinação das mídias requerendo maior cuidado na implementação.

Esses recursos, quando adequadamente planejados, despertam o interesse pelo aprendizado e configuram novas ecologias cognitivas na medida em que alteram os espaços de ensinar e aprender e os papeis de educandos e educadores. De acordo com Levy (1993), uma vez que o usuário pode participar ativamente, interferindo no processo com ações, reações, intervenções, ele torna-se receptor e emissor de mensagens que ganham plasticidade, permitindo a transformação imediata, criando novos caminhos, novas trilhas, novas cartografias, valendo-se do desejo do sujeito.

A construção flexível e colaborativa dos recursos e das atividades, que suportam a exploração da multidimensionalidade das representações de conhecimento, requer a reflexão sobre a prática docente e corrobora a afirmativa de Freire de que o ensinoaprendizagem é indissociável: "Não há docência sem discência” (Freire, 2003, p. 21-46) assim, não é possível ensinar sem aprender, nem aprender sem ensinar, neste processo as transformações ocorrem em duas vias envolvendo todos os agentes do aprendizado.

As Figuras 4, 5 e 6 apresentam alguns dos módulos criados pelos estudantes da DCG 1139, que exploram o caráter hipermídia dos materiais didáticos e a problematização do ensino. Nelas, é possível observar que os estudantes internalizaram os conceitos da interação e das múltiplas linguagens criando módulos com recursos variados, bem como a criação de atividades de estudo de caráter individual e colaborativo, flexibilizando assim, o processo de ensino-aprendizagem.

De acordo com Lobo da Costa (2008, p. 186):

A colaboração tem como características fundamentais a existência de diálogo, de negociação, e o contrato de reciprocidade e confiança. O diálogo é o que possibilita a troca de ideias e a participação efetiva, sobretudo se envolver todos os participantes.

Assim, além de flexibilizar o aprendizado adotando atividades tanto de cunho individual como colaborativo, os estudantes ao proporem as atividades no decorrer dos módulos didáticos de suas disciplinas, intencionam a troca de ideias, o posicionamento e o diálogo quando propõem as atividades "fórum" e "chat" do Moodle. Essas atividades requerem a negociação de concepções sobre um determinado assunto, promovendo a discussão e o amadurecimento de ideias, fortalecendo assim o espírito crítico, o aprendizado mútuo e a reflexão compartilhada.

Observa-se na Figura 4 que a construção do módulo realizada pelo estudante “A” apresenta uma linguagem de caráter dialógico, que é propiciado por meio do uso e rótulo (recurso educacional) e que conferem ao módulo o dialogo entre o material didático e o estudante. 


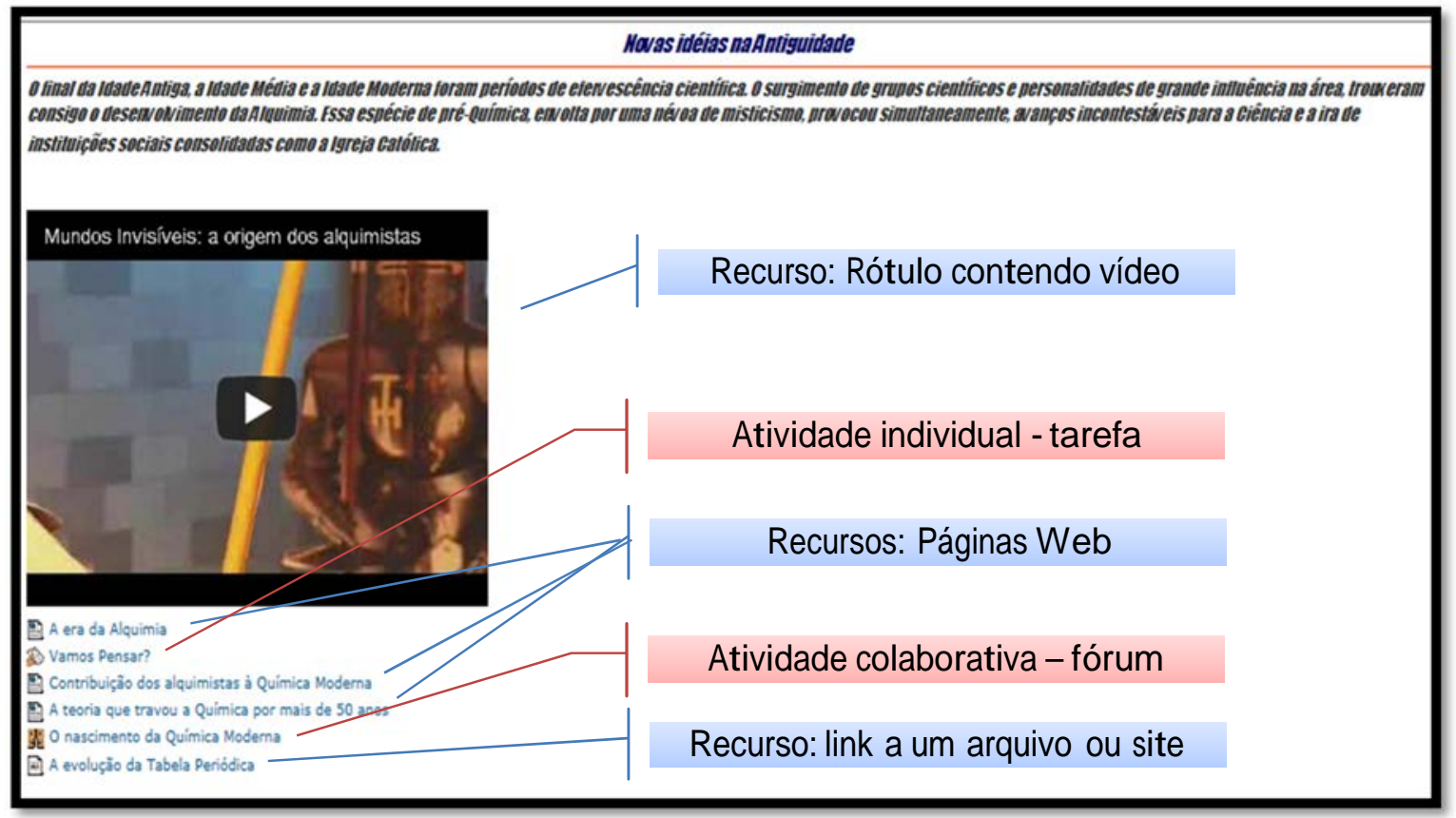

Figura 4 - Unidade 2 da disciplina História da Química desenvolvida pelo estudante “A”.

A simulação proposta pelo estudante “B” (Figura 5 -tracejado) é uma atividade que requer do estudante a tomada de decisões, potencializando a interatividade e rompendo com a unidirecionalidade do processo de ensino aprendizagem.

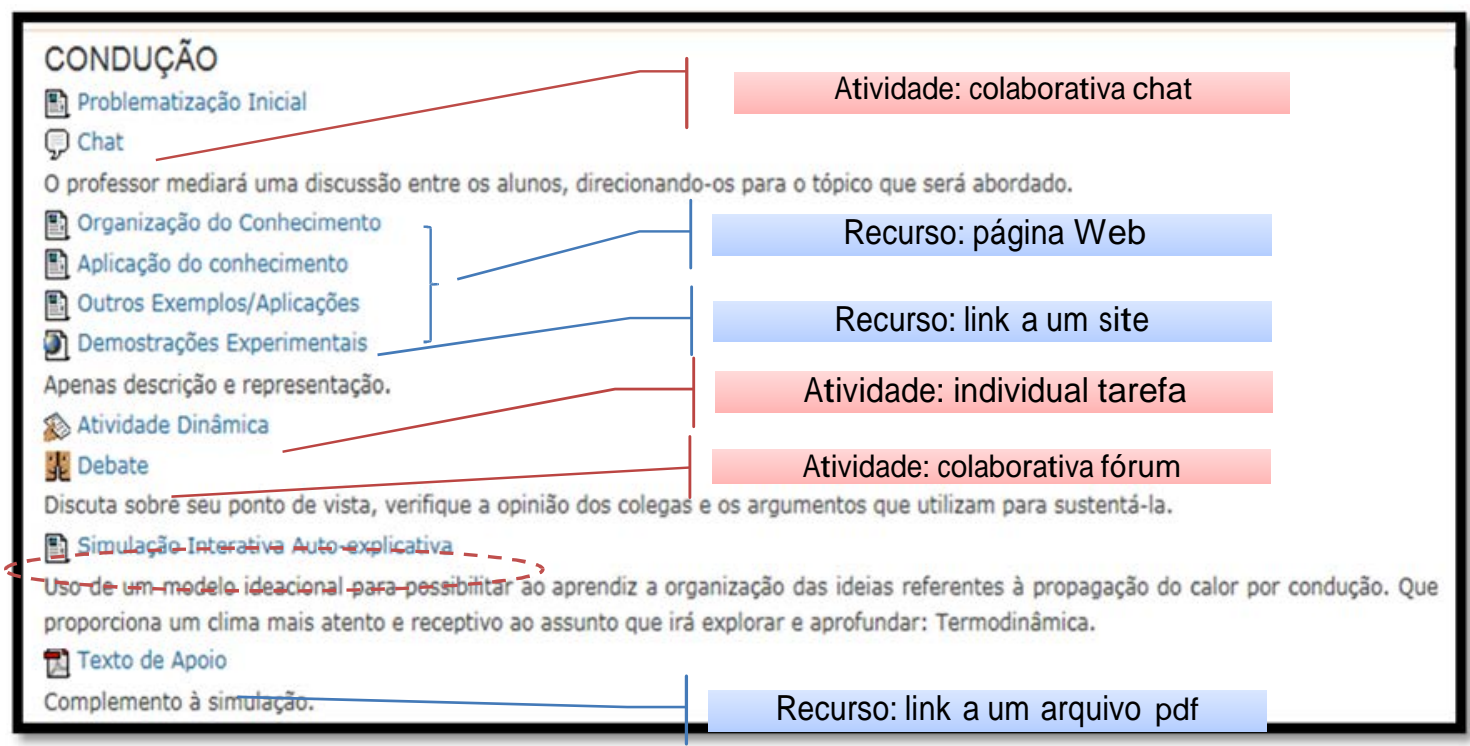

Figura 5 - Unidade 2 da disciplina Progressões das ideias da física proposta pelo estudante "B”

Primo e Cassol (1999) e Silva (2000), consideram que a interatividade possibilitada nos AVEA permite a realização de práticas mais colaborativas que promovem o intercâmbio de saberes, rompendo assim com a unidirecionalidade dos processos comunicativos promovendo desta forma, uma interação simultânea que enfatiza os aspectos quantitativos (número de pessoas interagindo) e principalmente qualitativos (variedade, riqueza e natureza das interações).

A temática escolhida pelo estudante “C”(Figura 6) para a elaboração da disciplina demonstra uma maturidade no que se refere a consciência crítica dos processos de formação de professores. O estudante faz uso de rótulo para destacar os itens abordados, e de recursos educacionais hipermídia (página Web e link a site). 
Destaca-se ainda que a atividade final proposta consiste numa Webquest, desenvolvida pelo próprio estudante no decorrer da DCG, que orienta a pesquisa na web.

Marachin e Axt (2010) ressaltam que o uso de recursos tecnológicos pode favorecer a constituição da Mente Coletiva, sendo um processo que transforma cada um de seus participantes na direção de novos conhecimentos e, fundamentalmente de novas atitudes epistemológicas, criando condutas crítico-criativas e autonomia para resolução de problemas e dificuldades específicas.

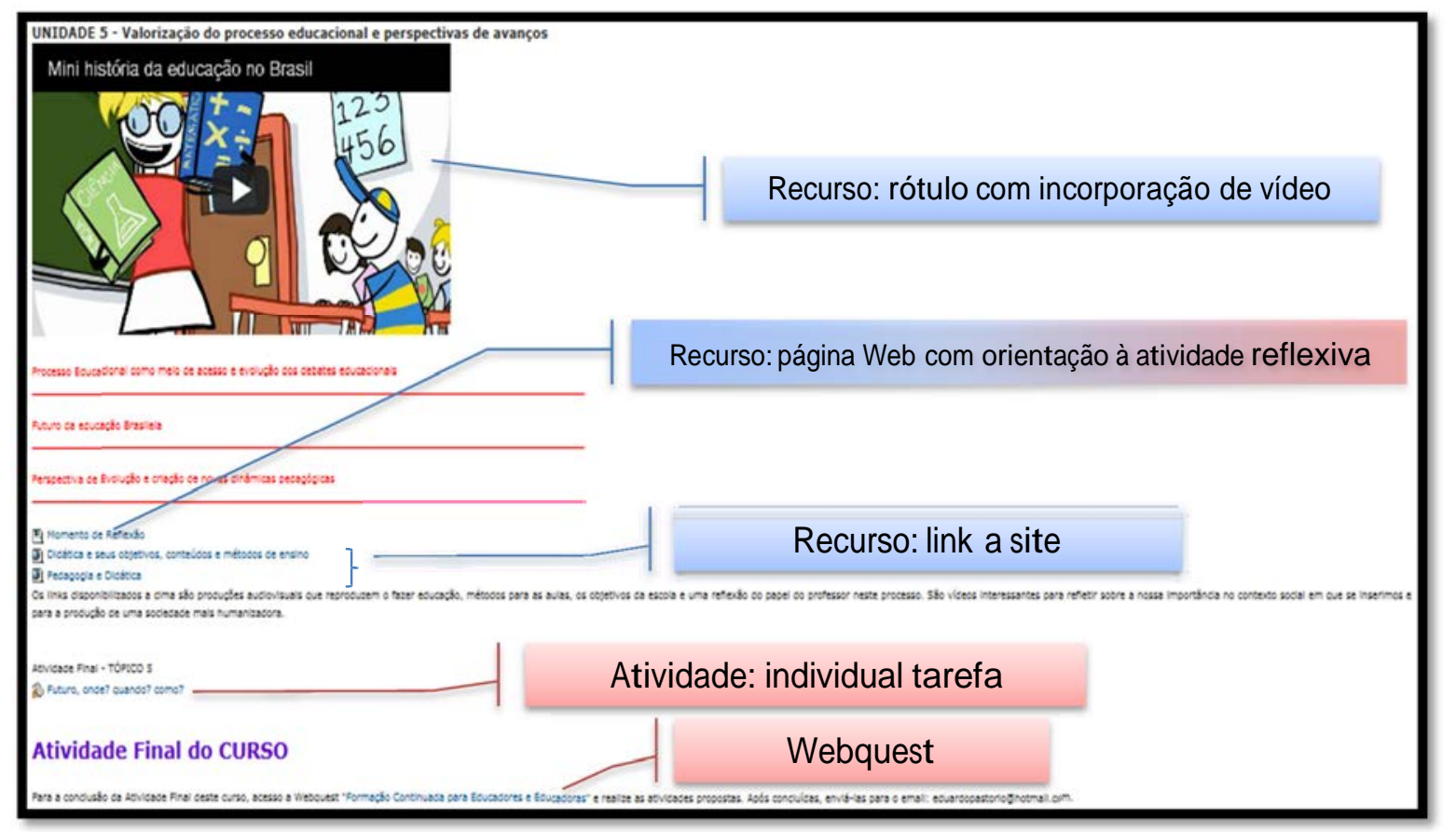

Figura 6 - Unidade 5 da disciplina Formação Continuada para educadores e educadoras das Redes de Ensino Educacionais, desenvolvida pelo estudante " $C$ ".

Práticas como as desenvolvidas na DCG 1139 tentam desfazer cenários apontados por alguns autores (Belintane, 2002; Lopes; Feitosa, 2011) de que alunos de cursos de licenciaturas específicas não estão sendo dotados de formação que os prepare a fim de utilizar as TIC pedagogicamente, sendo a formação inicial para as TIC geralmente precária e insuficiente. Além disso, incentivar e subsidiar teoricamente a utilização crítica das TIC pelos futuros professores é uma ação concordante com Sampaio e Leite (2001) quando afirmam que a alfabetização tecnológica de professores precisa ganhar espaço privilegiado nas IES formadoras e com Karsenti, Villeneuve e Raby (2008) ao afirmarem que estudantes de licenciatura preparados para o uso pedagógico das TIC têm mais chances de integrá-las à sua prática pedagógica.

Dessa forma, o professor universitário tem papel decisivo na capacitação técnico-didático-pedagógica dos estudantes para a familiarização com as TIC e com a aquisição da fluência para utilização das ferramentas e potencialidades hipermidiáticas do AVEA. Segundo Bastos et al (2012), o AVEA Moodle - com base nas possibilidades de comunicação e colaboração em rede mediadas pelo diálogo entre os sujeitos, na integração de diversas linguagens (hipertextual, audiovisual, hipermidiática) -, pode contribuir com a formação docente para o desenvolvimento de metodologias e materiais de apoio inovadores que incluam, de forma crítica, estudantes e professores no mundo atual. De acordo com Kenski (2010), educar para a inovação e a mudança significa planejar e implantar propostas dinâmicas de aprendizagem, em que se possam exercer e desenvolver concepções sóciohistóricas da educação nos aspectos cognitivo, ético, 
político, cientifico, cultural, lúdico e estético em toda a sua plenitude, garantindo a formação de cidadãos críticos, livres e criativos.

\section{Considerações Finais}

A construção de disciplinas no AVEA Moodle Social pelos estudantes, no âmbito da disciplina de Ciências Naturais e Exatas mediadas por Tecnologias Educacionais em Rede, configurou-se como um incentivo a autonomia e ao uso de tecnologias nas futuras práticas pedagógicas desses alunos.

Os professores em formação, enquanto autores do próprio material didático, foram desafiados a repensarem o ensino de suas áreas, incorporando metodologias inovadoras respaldadas pela hipermídia, além de realizarem a transposição didática dos conteúdos aprendidos no ensino superior (saber sábio) ao saber a ser ensinado aos estudantes da educação básica. A análise das disciplinas elaboradas demonstrou que houve compreensão por parte dos estudantes no que diz respeito às peculiaridades de um material didático digital elaborado em um AVEA e a importância da combinação dos recursos com as atividades, bem como, a mescla de atividades individuais e colaborativas ao longo do material. Por meio do procedimento de pesquisa-ação, instaurou-se uma atmosfera dialógica na realização da disciplina-pesquisa, durante a qual, mesmo em atividades individuais, houve mútua colaboração e trocas de experiências entre os participantes.

Os resultados apontam que ações desse tipo são misteres no decorrer da formação acadêmica docente, visando a fluência técnico-didático-pedagógica desses sujeitos face às exigências do mundo contemporâneo, que requerem um profissional crítico e autônomo, que saiba se comunicar e selecionar as informações pertinentes de forma crítica e efetiva.

Tal contexto exige dos professores universitários criatividade na condução das disciplinas para que a formação para a utilização das TIC se efetive e a aquisição desses conhecimentos não ocorra apenas de forma empírica, em decorrência necessidade, mas que respalde teoricamente os futuros docentes. Nesse sentido, levando-se em conta a resposta positiva por parte dos estudantes na aceitação e no desenvolvimento responsável da atividade proposta, o incentivo a esse tipo de formação ao longo de toda a graduação em Licenciatura, faz ganhar toda a educação brasileira.

\section{Referências}

ALMEIDA, V.P.; SILVA, J. C. A.. Estratégias Cognitivas para Aumento da Qualidade do Hiperdocumento que Contém o Material Instrucional para EAD. In: VI Simpósio sobre Fatores Humanos em Sistemas Computacionais - Mediando e Transformando o Cotidiano. Curitiba, 2004.

BASTOS, G. D. ; MARSHALL, D. ; BORGES, L. L. ; STORGATTO, G. A. ; BORGES, E. L. P.. O Moodle como mediador no processo de formação pedagógica: uma pesquisa-ação sobre a experiência de futuros professores em estágio extracurricular. Renote, v. 10, n.1, p.1-11, 2012.

BARIN, C.S.; ELLENSOHN, R.M.; MÜLLER, L.. Construção de significados e interação com, no e pelo computador: estudos problematizados no AVEA Moodle sobre uso das tecnologias da informação e comunicação Renote, v.10, n.1, p.1-10, 2012.

BELINTANE, C. Por uma ambiência de formação contínua de professores. Cadernos de Pesquisa. n. 117, p. 177-193, 2002.

CHEVALLARD, Yves. La transposición didáctica: del saber sabio al saber enseñado. Buenos Aires: Aique Grupo Editor, 1991.

DEBEVC, M. ; VENUTI , M.Z.; PELJHAN, Z.. E-learning material planning and preparation Maribor: Faculty of Electrical Engineering and Computer Science, 2003. 
FERES, G.G. Fluência e formas de acesso e uso da informação Científica: uma investigação na área de educação em Ciências. Revista Brasileira de Biblioteconomia e Documentação, Nova Série, São Paulo, v.4, n.1, p., 144. 2008.

FREIRE, P. Pedagogia da Autonomia - saberes necessários à prática educativa. São Paulo: Paz e Terra, 2003.

GIL, A.C. Como elaborar projetos de pesquisa. 4. ed. São Paulo: Atlas, 2002.

KARSENTI, T.; VILLENEUVE, S.; RABY C. O uso pedagógico das Tecnologias da Informação e da Comunicação na formação dos futuros docentes no Quebec. Educação e Sociedade, v. 29, n. 104, p. 865-889, out. 2008.

KENSKI, V.M. Educação e tecnologias o novo ritmo da informação. Campinas: Papirus. 2010. $141 \mathrm{p}$.

LISBÔA, E. S.; DE JESUS, A. G.; VARELA, A. M. L. M.; TEIXEIRA, H. S.;COUTINHO, C. P. LMS em contexto escolar: estudo sobre o uso da Moodle pelos docentes de duas escolas do Norte de Portugal. Revista Educação, Formação e Tecnologia. Universidade do Minho. Portugal, 2009.

LÉVY, P. As tecnologias de inteligência: o futuro do pensamento na era da informática. Rio de Janeiro: Editora_34, 1993. 208 p.

LOBO DA COSTA, N. M. Formação continuada de professores: uma experiência de trabalho colaborativo com matemática e tecnologia. . In: NACARATO, A. M. N.; PAIVA, M. A. V. (Orgs.) A formação do professor que ensina Matemática: perspectivas e pesquisas. - 1. Ed. 1. Reimp. - Belo Horizonte: Autêntica, 2008. 240p.

LOPES, R.; FEITOSA, E. Estágio extracurricular como um possível espaço de formação do professor para uso de tecnologias. Revista Ciência em Extensão. v.7, n.2, 2011.

MALLMANN, E. M; BARIN, C.S.; LAUERMANN, R.A. C; JACQUES, J.S.. Potencial da página web do Moodle para produção de recursos educacionais hipermídia. In: Anais $18^{\circ}$ CIAED, 2012.

MARASCHIN, C., AXT, M. O enigma da Tecnologia na Formação Docente. Brasília: Brasil, 1998. Disponível em:

http://webcache.googleusercontent.com/search?q=cache:PaCi6ciKHzkJ:http://www.c5.cl/ieinvestiga/acta s/ribie98/209.html+ecologia+cognitiva++levy+tecnologia\&hl=pt-BR\&biw=1280\&bih=673\&strip=1>. Acesso em: 14 de fev. 2012.

NOBRE, E.F.; et al. The multimedia technology in the production of didactic material for distance physics courses in Brazil . In: MPTL14 2009 Udine 23-27 September 2009.

PAPERT, S.; RESNICK, M. Technological Fluency and the Representation of Knoledge. Proposal to the National Science Foundation. MIT MediaLab, 1995.

PRIMO, A.F.T.; CASSOL, M.B.F. Explorando o conceito de: definições e interatividade taxonomias. Informática na Educação: teoria e prática, v.2, n.2, p. 65-80, 1999.

SAMPAIO, M. N; LEITE, L.S. Alfabetização tecnológica do professor. 5.ed. Petrópolis:Vozes, 2001.

SILVA, M. Sala de aula interativa. Rio de Janeiro: Quartet, 2000.

TRIPP, D. Pesquisa-ação: uma introdução metodológica. Educação e Pesquisa. v. 31, n. 3. São Paulo, 2005. 